\title{
Numerical Simulation Research on Welding Temperature Field of 304 Stainless Steel
}

\author{
Xu Kai ${ }^{* 1}$, Zhang Shu-quan ${ }^{2}$, Qiu Zheng-lai ${ }^{3}$
}

(1. Department of Mechanical Engineering, Anhui Technical College of Mechanical and Electrical Engineering, Wuhu 241000, China 2.Chinese Academy of Institute of Plasma Physics, Hefei 230000,China 3.Anhui Siait Cable Group Co.,LTD, Wuhu 241000,China)

Key words:304 stainless steel;welding;numerical simulation;temperature field;welding thermal cycle

Abstract: Using finite element software SYSWELD, we did three-dimensional dynamic simulation studies of 304 stainless steel flat TIG welding temperature field. The results obtained transient temperature field distribution chart and thermal cycling curve of feature points. Compared with literature data, the established numerical simulation model shows that it can simulate well the welding temperature field. The results offer important reference to study on stress and strain of welding seam, reducing welding stress and deformation.

304 stainless steel belongs to the austenitic stainless steel series, and is widely used in stainless steel application. 304 stainless steel has excellent corrosion resistance, heat resistance and low-temperature strength. Its welding performance is slightly better compared to other stainless steel, but poorer than low carbon steel. The thermal conductivity of austenitic steels is about $1 / 3$ of low carbon steels'. The thermal expansion coefficient is about 50\% larger than the low carbon steel. With the increasing of line energy of welding process, welding stress and deformation will get more serious, austenite grains tend to become coarse, which will lead to poorer welding performance ${ }^{[1-2]}$. In response to these problems, using the finite element software SYSWELD to study numerical simulation of 304 stainless steel welding temperature field, we intended for simulation studies of transient temperature field and thermal cycling curves of the welding process, analyzed temperature field and thermal cycling curve characteristics, and the relationship between phase transitions and temperature variations. This will provide the basis for study on stress and strain of welding seam, reducing welding stress and deformation, and also reference for the improvement of austenitic stainless steel welding performance.

\section{Establishment of Model}

Inhomogeneity of Welding temperature field is the main reason for the stress and deformation of welding seam, numerical simulation for welding temperature field is the base of the analysis and study of the welding seam stress and strain fields.

\section{Establishment of Mathematical model}

As high welding heating temperature, short high temperature residence time and fast cooling rate in the welding process, the temperature field constantly changes dramatically with the movement of the heat source and the changes over time and space. Therefore, the analysis of welding temperature field is of a typical nonlinear transient issue, and physical properties of materials are also changing in dramatic ways with temperature. Taking into account material flow rate in the solid material is equal to zero, heat transfer calculation is only necessary in the

\footnotetext{
*Brief introduction to the author: xu kai(1974.6-), male, master of engineering, associate professor. Main direction studied: welding and numerical simulation technology. E-mail:ahjdxukai@126.com, Tel: 18298269028
} 
surrounding solid metal of the welding pool. So the study of welding temperature field focused on heat conduction. The control equation of heat conduction is:

$$
\rho c \frac{\partial T}{\partial t}=\frac{\partial}{\partial \chi}\left(\lambda \frac{\partial T}{\partial \chi}\right)+\frac{\partial}{\partial y}\left(\lambda \frac{\partial T}{\partial y}\right)+\frac{\partial}{\partial Z}\left(\lambda \frac{\partial T}{\partial Z}\right)+\bar{Q}
$$

Where, $\rho, \mathrm{c}$ and $\lambda$ are the material density, specific heat capacity and thermal conductivity, $\bar{Q}$ is inner heat source strength, which are functions of temperature.

\section{Simplified finite element model}

The research object is flat butt welding and welding seam is located in the middle of the plate. With 304 stainless steel as base metal, numerical simulation geometry dimensions for welding temperature field are of $60 \times 60 \times 6(\mathrm{~mm})$. Using TIG welding, finite element geometry model is shown in Figure 1 below.

\section{Key Issues of FEM}

\section{Selection of welding heat source}

Currently the main heat source modes include Rosenthal parsing mode, Gaussian distribution heat source, double elliptical distribution heat source, semi-ellipsoidal distribution heat source, double ellipsoid distribution heat source and so on $^{[3]}$. SYSWELD software provides models for these various types of heat sources, including double ellipsoid heat source model. As heat flux described by the double ellipsoid model is of distribution within the ellipsoid, which can exactly reflect the effects that welding beam in the depth direction has on welding parts heating. It can be more accurate to simulate welding temperature field ${ }^{[4]}$. Accordingly, using a double ellipsoid heat source model suitable for TIG welding, combining with the actual shape and size of welding seam profile, using heat source checking tools provided with SYSWELD software, entering the selected welding process parameters for heat source checking, we get heat source model shown in the figure 2 below.

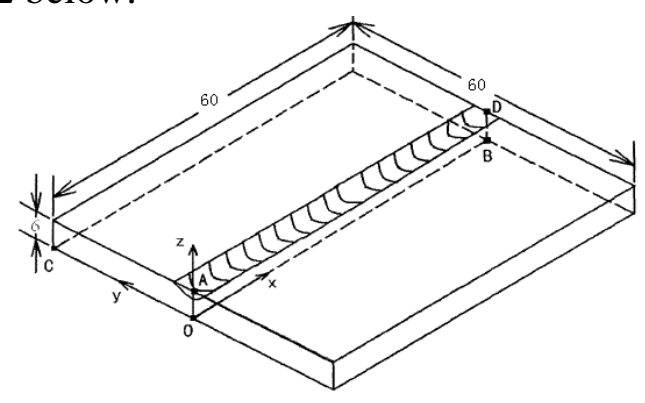

Fig. 1 Finite element geometry model

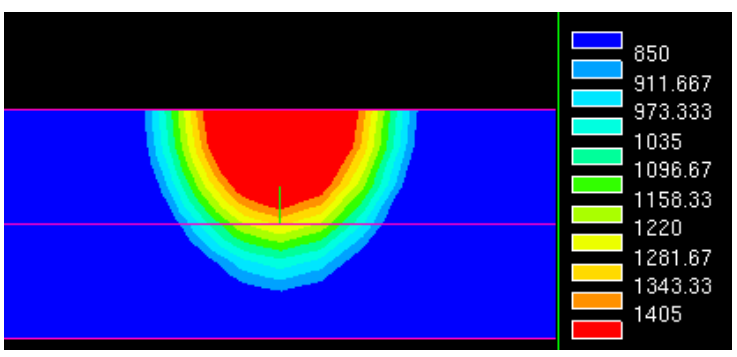

Fig 2 Heat source model after checking

\section{Physical property parameters of material}

Thermo-physical property parameters of material are function of temperature, but the thermo-physical property data of many materials (such as specific heat, thermal conductivity) is blank at high temperature, especially when close to the molten state. Parameters at certain temperature in this paper use extrapolation and interpolation method. Some physical performance parameters of 304 stainless steel can be found in Chinese Steel Wikipedia website ${ }^{[5]}$, as shown in Table 1-1. 
Table 1-1 Some of the physical property parameters of 304 stainless steel

\begin{tabular}{|c|c|c|c|c|c|c|c|c|c|}
\hline \multirow{3}{*}{$\begin{array}{l}\text { Stainless } \\
\text { steel type }\end{array}$} & \multirow{3}{*}{$\begin{array}{l}\text { Density } \\
\mathrm{g} / \mathrm{cm}^{3}\end{array}$} & \multirow{3}{*}{$\begin{array}{l}\text { Specific } \\
\text { heat } \\
\text { capacity } \\
\mathrm{J} / \mathrm{kg} \cdot \mathrm{K}\end{array}$} & \multirow{3}{*}{$\begin{array}{l}\text { Elasticity } \\
\text { modulus } \\
20^{\circ} \mathrm{C}(\mathrm{Mpa})\end{array}$} & \multicolumn{3}{|c|}{ Thermal expansion coefficient } & \multicolumn{3}{|c|}{ Heat conductivity } \\
\hline & & & & & $\alpha\left(10^{-6} / \mathrm{K}\right)$ & & \multicolumn{3}{|c|}{$\lambda(\mathrm{W} / \mathrm{m} \cdot \mathrm{k})$} \\
\hline & & & & $20 \sim 100^{\circ} \mathrm{C}$ & $20 \sim 300^{\circ} \mathrm{C}$ & $20 \sim 500^{\circ} \mathrm{C}$ & $20^{\circ} \mathrm{C}$ & $100^{\circ} \mathrm{C}$ & $300^{\circ} \mathrm{C}$ \\
\hline 304 & 7.85 & 500 & 19900 & 16 & 17 & 17 & 15 & 18 & 21 \\
\hline
\end{tabular}

\section{Meshing and time steps}

Welding is a dramatic change process in temperatures over time and space and the temperature gradient is large, so welding seam and the vicinity mesh should be very fine and mesh can be coarse in a place away from the welding seam so as to consider contradiction between computation accuracy and speed. In the welding stage, calculation step is generally controlled at about $0.1 \mathrm{~s}$. Only when the welded parts are cooled to a certain temperature before considering method of variable step size, needing to gradually increase time step. To obtain a satisfactory transient temperature field of welding, grid unit at welding seam has better be in the control of $2 \mathrm{~mm}$ or less ${ }^{[6]}$. Therefore, it is critical to reasonably mesh and set time step. This paper intends to adopt uniform meshing in the welding seam with grid unit of $1 \mathrm{~mm}$ and using transition mesh elsewhere namely coarse mesh whose unit grid is greater than $1 \mathrm{~mm}$. Time step at welding phase is set to 0.2 seconds while the time step at cooling stage is larger, generally greater than 0.2 seconds.

\section{Simulation results and analysis}

\section{Welding temperature field distribution features}

Taking TIG welding and the positive polarity DC as welding method, the welding current is $170 \sim 200 \mathrm{~A}$ and welding voltage is $13 \sim 18 \mathrm{~V}$, with welding speed of $5 \mathrm{~mm} / \mathrm{s}$ and welding thermal efficiency of 0.68. Using SYSWELD software to generate animation feature, it can display the dynamic change of temperature field in the entire welding process. Following several figures show clearly dynamic change of temperature field in the welding and cooling process. As Figure 3 shows distribution of welding temperature field at different times. Figure 3 (a), (b), (c), (d), (e) shows the temperature field cloud picture at welding and 3 (f) shows the temperature field cloud picture at cooling.

As Figure 3 shows, temperature at each point on the joint changes over time. The temperature rapidly rises at the start of welding. As figure (a) to (b) show, during the time from 0.2 seconds to 0.8 seconds, the maximum temperature rises rapidly from $640.5{ }^{\circ} \mathrm{C}$ to $1343.2{ }^{\circ} \mathrm{C}$ and forms a quasi-stable state temperature field in 4.4s. As figure (c), (d) shows, the maximum temperature changes a little with value of respectively $1690.8{ }^{\circ} \mathrm{C}$ and $1691.3{ }^{\circ} \mathrm{C}$. Each point around the heat source moves with the heat source in constant temperature. In 12 seconds after welding, the temperature reached the highest point of $1919.9{ }^{\circ} \mathrm{C}$, as shown in Figure (e). Then with a rapid temperature drop and in 4 seconds from the start of cooling, the maximum temperature is only $719.7^{\circ} \mathrm{C}$, as shown in Fig (f).

\section{Welding thermal cycle curve for different points at welding seam centerline}

Use the time-history processor in the SYSWELD, you can extract temperature thermal cycle curves of the vertical welding seam node and the welding seam center node. Taking six equidistant points from the center line of the welding seam, the nodes were 3553, 3673,3793,3913,4033 and 4153. By the time domain processing, temperature and time course of change is shown in Figure 4, 
which is welding thermal cycle curve of points at the center line of the welding seam.

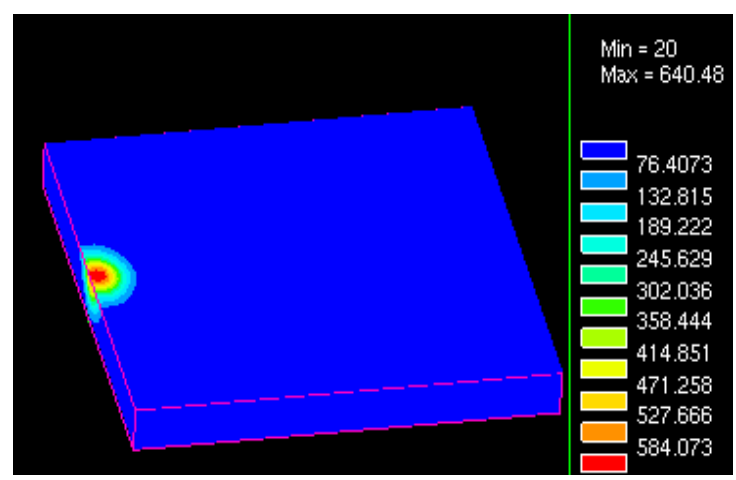

(a) Heating for 0.2 seconds

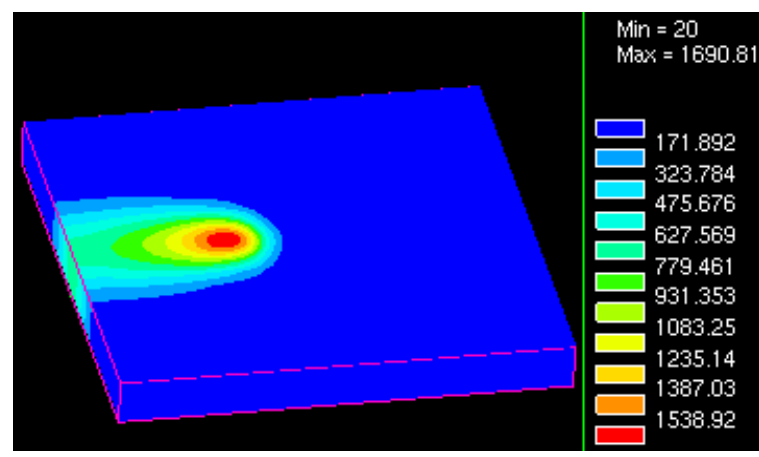

(c) Heating for 4.4 seconds

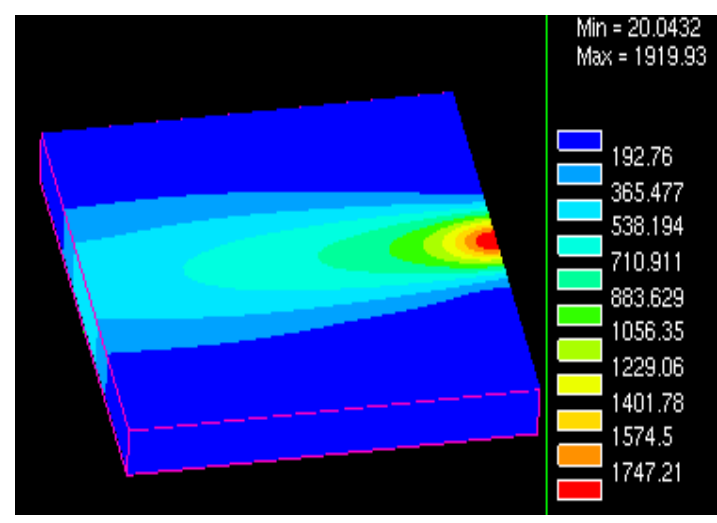

(e) Heating for 12 seconds

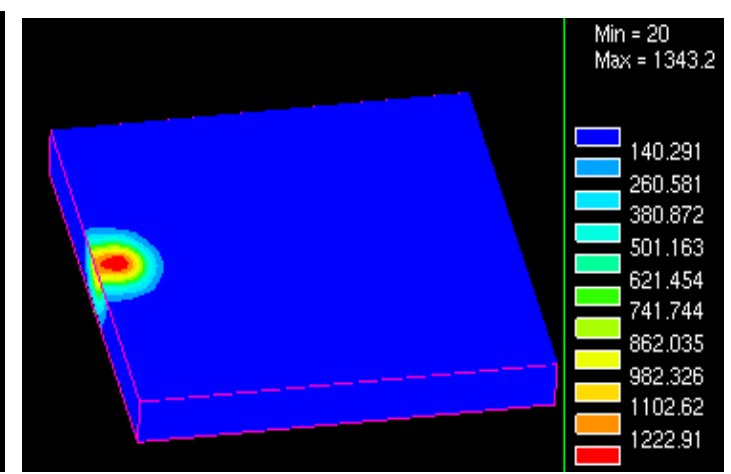

(b) Heating for 0.8 seconds

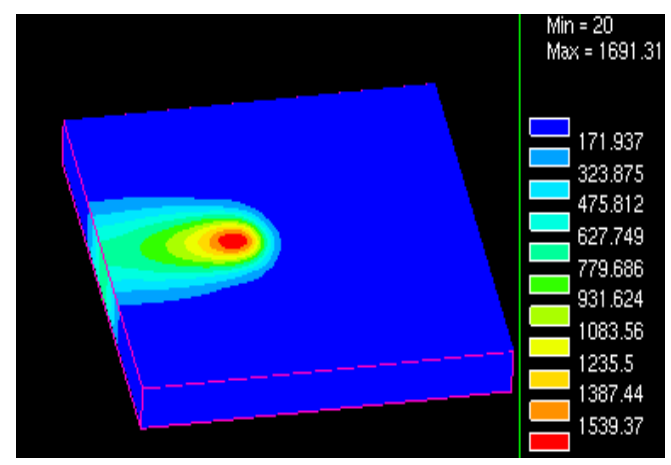

(d) Heating for 4.6 seconds

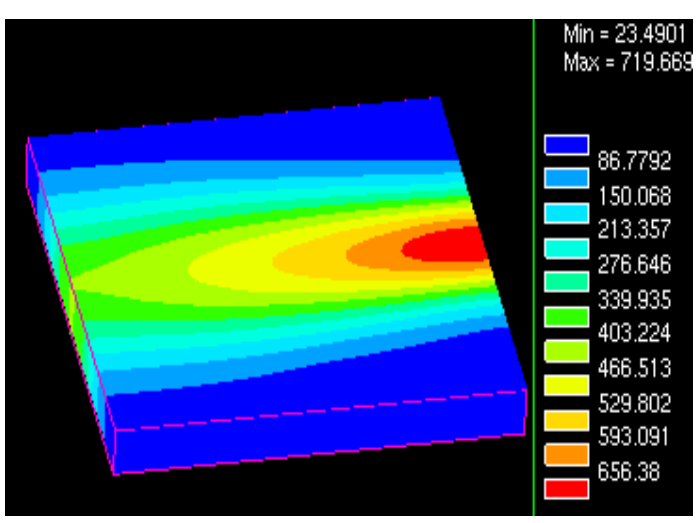

(f) Cooling for 4 seconds

Fig 3 Temperature field distribution of welding plate at different time moments

As Figure 4 shows, for each node along the center line of the welding seam, their temperature thermal cycling curves are of substantially similar characteristics with rapid rising and then cooling. The maximum temperatures are all above $1600{ }^{\circ} \mathrm{C}$ which is more than the melting temperature (304 stainless steel melting point in the range $1398{ }^{\circ} \mathrm{C} \sim 1454{ }^{\circ} \mathrm{C}$ ). In the welding process, the heat source moves along welding pieces and the temperature of each point on the welding pieces change from low to high over time. After reaching the peak value, the temperature changes from high to low. Heating rate of each point is significantly larger than the cooling rate, which is of reason that as the heat source away from the node, molten bath at the node starts cooling but still heated by molten bath behind it and thereby slowing the cooling rate. In cooling, the temperature of the points tends to a certain value until reaching the average temperature of welding pieces. From Figure 4, it can also be seen that temperature heat cycle curve shape of the selected six nodes is basically same, 
which thus indicates that all six nodes have reached the quasi-steady-state temperature field. It also can be seen that junction temperature experienced rapid heating and cooling process during welding, which is basically in line with the literature ${ }^{[7]}$.

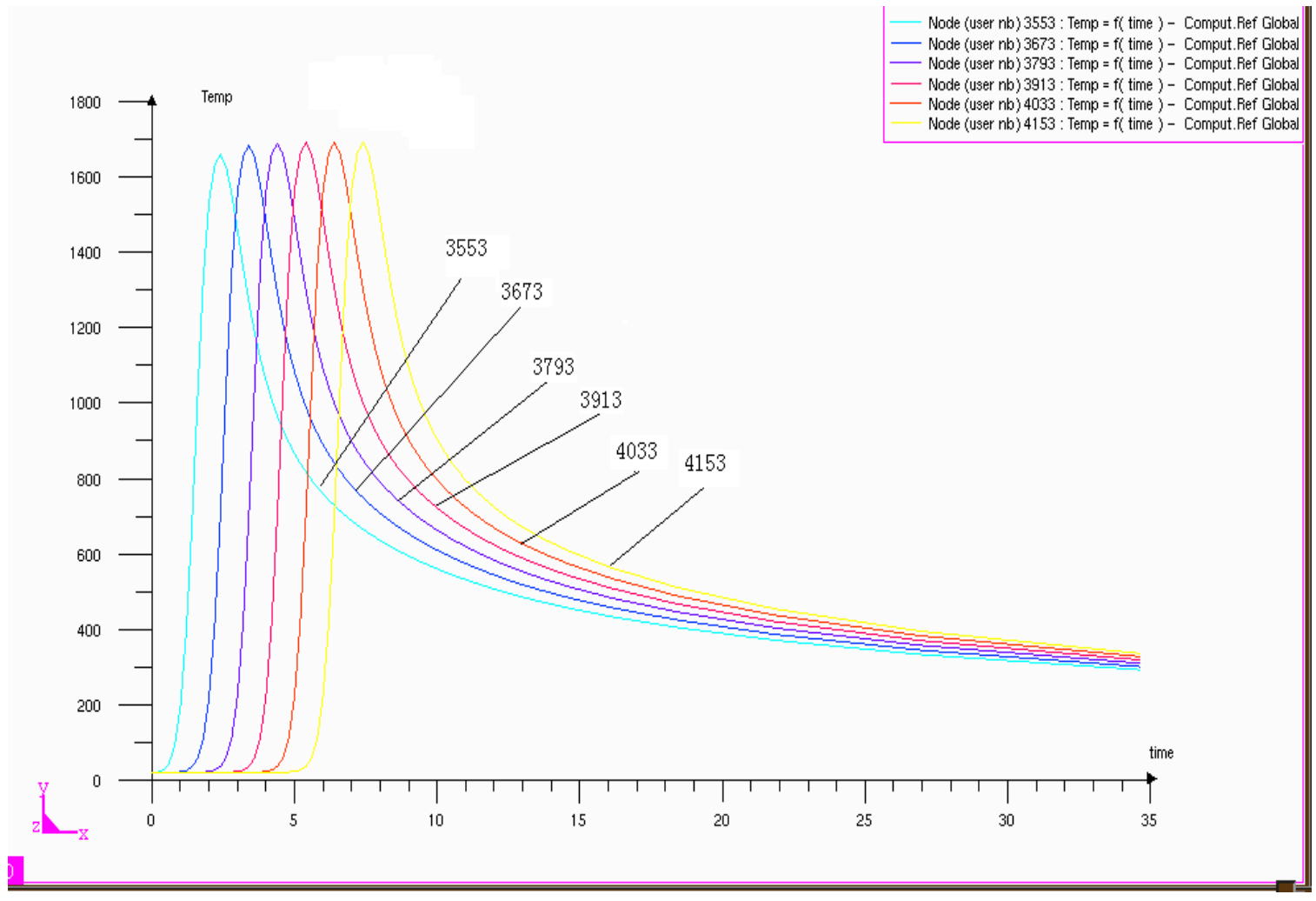

Fig.4 welding thermal cycle at the center points

Welding thermal cycle curve at each point in direction of vertical welding seam (width)

According to SYSWELD temperature field simulation results, thermal cycle curves can be obtained at each point away from the welding seam centerline respectively with the distances of 0mm, $2 \mathrm{~mm}, \quad 3 \mathrm{~mm}, \quad 5 \mathrm{~mm}, \quad 7 \mathrm{~mm}, \quad 10 \mathrm{~mm}$ and $13 \mathrm{~mm}$. The nodes are $3673,12901,14663,7075,14480,14419$ and 14358, as shown in figure 5 below.

During the welding process, the temperature of the workpiece varies with the moving heat source, according to Figure 5. The temperature change from low to high over time and when reaching the maximum value, it changes from high to low. The temperature rising rate is significantly faster than one of temperature drop. The temperature variation is the same as the case in welding seam center line. It is also reflected that thermal cycles are different at points with different distances from the welding seam at both sides of the welding seam. The closer points from the welding seam, the higher the maximum heating temperature and the farther point, the lower maximum heating temperature, which is also basically consistent with the literature ${ }^{[7]}$.

\section{Conclusion}

(1) When the temperature field in 4.4 seconds get to the quasi-steady-state, then temperature field distribution remain basically unchanged, evenly moving forward as time goes.

(2) When the thermal cycle curve of central node of welding seam is basically same, it indicates that the temperature field has been in a quasi-steady state.

(3) With different points away from the center of the welding seam, the thermal cycle curves are different. The closer the point away from the welding seam, the greater heating rate, the higher 
the peak temperature and the greater cooling rate.

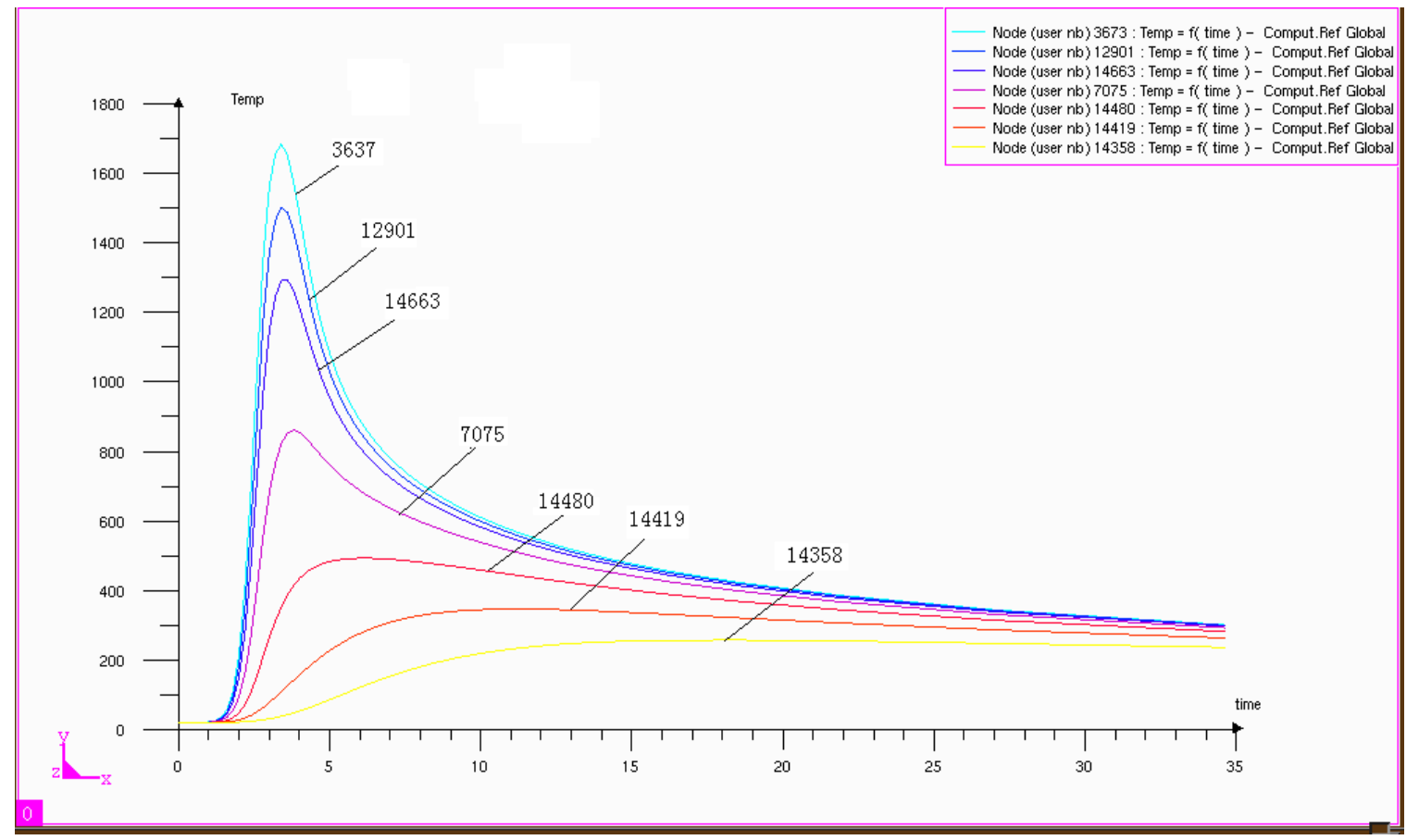

Figure 5 Welding thermal cycle curve from the different positions of the welding seam center

\section{References}

[1] Shen Xianpu. The Present Condition and the Prospect of Dual-phase Steels[J]. Materials for Mechanical Engineering, 1988, (1):1-4.

[2] Li Weiwei, Gong Shaotao, Xiong Qingren. Weldability and Welding technique of 2205 Duplex Stainless Steel[J]. Hot Working Technology, 2006, 35 (3) :36-38.

[3] Cheng Jiuhuan. Research Progress of Welding Heat Source Model[J]. Welding Technology, 2004, 33 (1):13-17.

[4] Mo Chunli, Qian Bainian, Guo Xuming. The Development of Models about Welding Heat Soures Calculation[J]. Transactions of The China Welding Institution, 2001,6 (22) :93-96.

[5] http://baike.gqsoso.com/edition-view-4435-1,2010-02-21

[6] Wang Jianhua. Numerical Simulation Technology and Its Application in Welding[M]. Shanghai: Shanghai Jiaotong University Press, 2003.

[7] The Welding Institution of The Chinese Mechanical Engineering Society, Welding Handbook: Volume 2 Welding Materials [M]. 2nd edition. Beijing: Mechanical Industry Press, 2003. 